\title{
Comparative Study between the Benefit of Pre-Emptive Pregabalin and Gabapentin on Acute Postoperative Pain for Elective Gynecological Surgery
}

\author{
Gamal A. Abd Elhameed* ${ }^{*}$, Simon Armanios \\ Ain Shams University, Cairo, Egypt \\ Email: *gem6082@yahoo.com, simondr106@gmail.com
}

How to cite this paper: Elhameed, G.A.A. and Armanios, S. (2019) Comparative Study between the Benefit of Pre-Emptive Pregabalin and Gabapentin on Acute Postoperative Pain for Elective Gynecological Surgery. Open Journal of Anesthesiology, 9, 227-237.

https://doi.org/10.4236/ojanes.2019.912023

Received: November 19, 2019

Accepted: December 15, 2019

Published: December 18, 2019

Copyright $\odot 2019$ by author(s) and Scientific Research Publishing Inc. This work is licensed under the Creative Commons Attribution International License (CC BY 4.0).

http://creativecommons.org/licenses/by/4.0/

(c) $\underset{\mathrm{EY}}{\mathrm{C}}$ Open Access

\begin{abstract}
Gabapentin, and pregabalin had been used in analgesic field some studies. This double blind randomized clinical trial was conducted to evaluate the pre-emptive use of gabapentin $900 \mathrm{mg}$ and pregabalin $300 \mathrm{mg}$ in reducing postoperative pain. Methods: A total number of 75 patients undergoing lower gynecological procedures were prospectively randomized, into three groups (group A, B and C), each group including 25 patients with total 75 patients. Pregabalin, gabapentin or placebo, the pain was assessed on a visual analogue scale (VAS) at $0,6,12,18 \& 24$ hours postoperatively. Duration of effective analgesia was documented, and administration of extra analgesic doses of meperedine required in the first 24 hours. Results: Patients in the gabapentin or pregabalin had significantly lower VAS scores at 6,12,18 and 24 hours, than those in the placebo group. As for rescue analgesia with mepredine consumed in the gabapentin, and pregabalin were significantly less than in the placebo. As for the complications, both drugs had increased incidence of nausea, vomiting and dizziness postoperatively, while no significance was found between all groups as regard hypotension, bradycardia and shivering. Conclusion: Preoperative use of pregabalin or gabapentin provides comparable but significant prolonged postoperative analgesia, less nausea and vomiting compared to placebo after gynecological surgeries. However, it was associated with increased incidence of postoperative dizziness.
\end{abstract}

\section{Keywords}

Gabapentine, Pregabalin, Postoperative Pain 


\section{Introduction}

The relief of postoperative pain is a subject of concern as it has been receiving an increasing amount of attention in the past few years [1], as failure to relieve pain is morally and ethically unacceptable.

The goals of pre-emptive analgesia are to decrease acute pain after tissue injury, and to inhibit the continuity of post-operative pain causing chronic pain [2]. Drugs such as local anesthetics injection, opioids, non-steroidal anti-inflammatory drugs, cyclooxygenase- 2 inhibitor, paracetamol, gabapentin, pregabalin, clonidine and dexmedetomidine have been used as pre-emptive analgesics [3].

Surgical stimulation causes central and peripheral sensitization. Antihyperalgesic drugs have shown improvement of postoperative pain by preventing the development of central sensitization.

Some clinical trials of gabapentin, given before a variety of surgical procedures producing visceral and somatic injury, have found significant reduction in postoperative analgesic needs or a reduction in early and late postoperative pain scores [4].

In this study, we compared the effect of preventive single dose of gabapentin or pregabalin on the acute postsurgical pain after elective lower abdomino-pelvic gynecological surgical procedures under spinal anesthesia, in order to neglect the possible analgesic effects of general anesthetics on the results of this study, to evaluate and compare the effect of the drugs on vital parameters, to study the post-operative requirement of analgesics and to compare the side effects of pregabalin and gabapentin.

\section{Methods}

In this prospective randomized comparative study, using a computer-derived random number sequence, women were divided by means of closed envelopes into three groups (group A, B and C), each group including 25 patients with total 75 patients, sample size depending on a the average $6 \mathrm{hr}$ VAS previous study of experimental drugs with a power of $80 \%$, and confidence interval o $90 \%, 22$ patients reuired per group increased to 25 avoiding drop outs.

Ethical approval from our ethical committee, and individual conscent for participation was taken

Inclusion criteria: Female patients of American society of Anesthesiologists (ASA) grade I or II. Aged 20 - 60 years. Gynecological surgeries only under spinal anesthesia were included in this study.

\section{Exclusion criteria:}

Inability to cooperate.

Patients with contraindications to spinal anesthesia.

Patients with major neurological, cardiovascular, metabolic, respiratory, renal disease or coagulation abnormalities.

Body mass index (BMI) more than 30. 
Emergency surgery.

History of allergy to gabapentin \&/or pregabalin.

Patients on regular treatment with gabapentin, pregabalin, opioids, tramadol, sedatives or anticonvulsants.

Limited or insufficient respiratory reserve.

An hour before surgery, vital parameters including pulse rate and blood pressure (BP) of all the patients were recorded in pre-anesthetic room and then the drug selected for the study was given with a water sip (neither the anesthetist nor the patient knew the type of the drug administered).

Group A: received three placebo capsules with similar shape and color.

Group B: received $900 \mathrm{mg}$ of gabapentin (three $300 \mathrm{mg}$ capsules).

Group C: received $300 \mathrm{mg}$ of pregabalin (three $100 \mathrm{mg}$ capsules).

After detailed pre-anesthetic evaluation, routine and specific investigations, patients were informed regarding the type of study, and the visual analog scale (VAS) for pain assessment $(0 \mathrm{~cm}=$ no pain, $10 \mathrm{~cm}=$ worst pain imaginable $)$ was introduced to every patient (Figure 1).

In the Operation room, intravenous (IV) line was secured by using 18 Gauge cannula and preoperative vitals as (Blood pressure, peripheral pulse, respiratory rate, $\mathrm{SpO}_{2}$ ) were recorded. coloading with lactated ringer solution at a rate of 15 $\mathrm{ml} / \mathrm{kg} / \mathrm{h}$. Spinal anesthesia was given at the L3-L4 interspace and a volume of 3.5 $\mathrm{ml}$ of $0.5 \%$ bupivacaine heavy injected over 30 seconds through a 25 Gauge spinal needle. Patient was placed in the supine position with minimal $15^{\circ}$ head down tilt to achieve the level of block of T10.

Intraoperative fluid therapy was used in avoidance of spinal anesthesia-induced hypotension. Sensory level assessment was through the loss of cold sensation while Bromage score was used in motor block assessment [6].

Postoperatively, analgesia was administered whenever VAS score was greater than 4 , in the form of paracetamol 1 gm given IV every 8 hours regularly for the first 24 hours, and meperedine $50 \mathrm{mg}$ given intramuscularly (IM) repeated on demand as rescue analgesia at intervals not less than 6 hours each (before which VAS was recorded).

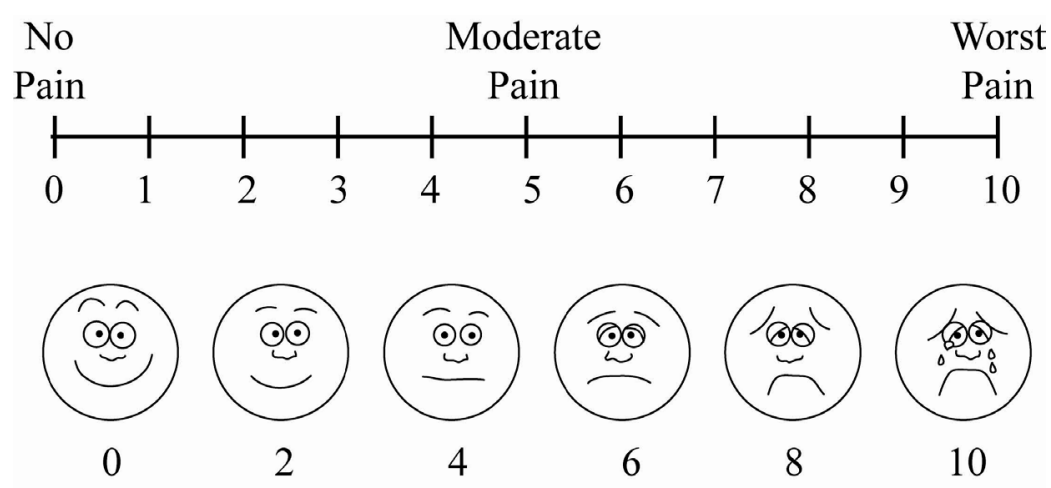

Figure 1. Correlation between Visual and verbal scale [5]. 1 - $3=$ mild pain, 4 $6=$ moderate pain $\& 7-10=$ severe pain 1 . 


\section{Data collection:}

Patients were kept under observation for a total period of 24 hours postoperatively and the following data were recorded: Pain scores, carried out by VAS at 0 , $6,12,18 \& 24$ hours postoperatively. Duration of motor block was measured, as the time from establishment of complete motor block after intrathecal drug administration, assessed by Bromage scale (Bromage score of 4) till regaining full muscle power (Bromage score of 1 ), with recording VAS score at the time of regaining full muscle power. Duration of effective analgesia was derfined, as the time from intrathecal drug administration to the patient's first request for analgesic i.e. administration of first doses of either meperedine and/or paracetamol, either in the recovery room or in the ward. The total number of doses of meperedine required in the first 24 hours. Occurrence of intra or postoperative attacks of hypotension and/or bradycardia that required treatment. Episodes of postoperative shivering, nausea, vomiting, and dizziness.

N.B. Pain scores and duration of effective analgesia were considered as the primary outcome measures.

\section{Statistical analysis:}

Data were analyzed using Statistical Program for Social Science (SPSS) version 21.0. Quantitative data were expressed as mean \pm standard deviation (SD) for parametric variables. Qualitative data were expressed as frequency and percentage.

The following tests were done: A one-way analysis of variance (ANOVA): when comparing between more than two means of parametric variables. Mannwhitney $U$ test was performed for non-parametric values as median and interquartile ranges. Chi-square (X2) test was used to compare proportions between two qualitative parameters. Probability (P-value): P-value $<0.05$ was considered significant. $\mathrm{P}$-value $>0.05$ was considered insignificant.

\section{Discussion}

High-quality pain control after surgery is still a major challenge. Pain is one of the causes for delayed discharge. The degree of postoperative pain is multifactorial and depends on variables such as type and duration of the surgery, type of anaesthesia and analgesia used, and the patient's mental and emotional state.

Preemptive analgesia before surgical stimulus is an arising method in avoidance of allodynia and chronic pain development.

Gabapentin and pregabalin have antiallodynic and antihyperalgesic properties useful for treating neuropathic pain and therefore may be beneficial in acute post-operative pain management [7].

Although there is a lot of studies for comparison of both this study showed that both $\mathrm{Yu}$ et al. [8]. Gabapentin and pregabalin administered in a single dose preoperatively, has significantly prolonged the duration of effective analgesia, decreased the rescue analgesia requirements and decreased the opioid associated side effects. These benefits were not associated with intra or postoperative he- 
modynamic variations. However, it was associated with increased incidence of postoperative dizziness and sedation.

Multi model analgesia has become the standard of practice to treat severe postoperative pain following orthopedic surgery [9]. This practice involves the use of different classes of analgesics with different route of administration to: Provide better pain relief at rest and with movement. Decrease opioid consumption. Decrease analgesics side effects [10].

Along with our study, Ghai and his colleague [11] found pregabalin $300 \mathrm{mg} 1$ - $2 \mathrm{~h}$ preoperative before abdominal hysterectomy is superior to $900 \mathrm{mg}$ gabapentin and placebo, in their study they used a higher dose of pregabalin which was associated with excess somnolence up to $18-24$ hours after surgery they also used other two types of analgesics as tramadol and diclofenac.

Bafna and colleagues [12], have studied preemptive effect gabapentin and pregabalin for acute post-operative pain after operation under spinal anesthesia. In their study, patients received a single dose of placebo capsule (group A), gabapentin $600 \mathrm{mg}$ (group B) or pregabalin $150 \mathrm{mg}$ (group C). A significantly longer mean duration of effective analgesia in group $\mathrm{C}$ was observed compared with other groups $(P<0.001)$. Similarly, in our study, a significantly longer duration of effective analgesia in group C: pregabalin group, and group B: gabapentin group was observed in comparison with the placebo group, with the duration being longer in the pregabalin group.

Similar results were obtained by Kohli and colleagues [13]. Their randomized, double-blind, placebo-controlled trial was conducted in 150 patients undergoing hysterectomy under spinal anaesthesia, who were divided into three groups, group I control group, group II received $150 \mathrm{mg}$ pregabalin 1 hour before surgery and group III received $300 \mathrm{mg}$ pregabalin 1 hour before surgery. In their study they observed that the pregabalin group showed reduced anxiety scores which showed no difference between pregabalin $150 \mathrm{mg}$ and pregabalin $300 \mathrm{mg}$ groups. The time of rescue analgesia required by the patients was increased in pregabalin groups, with more effective prolongation of analgesia after spinal anaesthesia in the pregabalin $300 \mathrm{mg}$ group. This prolongation in the analgesia was correlating well with the half-life of pregabalin which is 4.6 to 6.8 hours, and was not associated with any hemodynamic instability. On the other side, patients received pregabalin has suffered an increase incidence of dizziness more than the other groups.

While no statistical difference as found as regard sedation, nausea or vomiting.

Patient satisfaction was better with pregabalin $300 \mathrm{mg}$ group than $150 \mathrm{mg}$ group and much better than with the control group. The reduction in mean blood pressure and heart rate was seen in all groups, mostly due to the effect of spinal anaesthesia. In their study they concluded that preemptive administration of pregabalin before hysterectomy under spinal anaesthesia will prolong the neuraxial block, help in immediate postoperative analgesia and reduce the rescue 
analgesia requirements, with $150 \mathrm{mg}$ being the optimal dose.

On the contrary, the study conducted by Short and his colleagues [14], couldn't reach the same conclusion as the previous studies and couldn't even replicate the positive results from a previous study from their own group evaluating the analgesic benefits of gabapentin $600 \mathrm{mg}$ given orally preoperatively to women undergoing elective cesarean delivery. In their study they randomized 132 women undergoing elective cesarean delivery into 3 groups to receive 300 or $600 \mathrm{mg}$ oral gabapentin, or placebo, 1 hour before surgery. Spinal anesthesia and postoperative analgesia were instituted, including intrathecal fentanyl and morphine, oral diclofenac and acetaminophen, and systemic morphine as required. They did not observe an improvement in pain scores with either 300 or $600 \mathrm{mg}$ gabapentin and concluded that a single preoperative dose of $300 \mathrm{mg}$ or $600 \mathrm{mg}$ gabapentin did not improve post cesarean pain management or maternal satisfaction in the context of a multimodal analgesic regimen inclusive of intrathecal morphine. These differences in results can be attributed to their usage of intrathecal morphine which prolongs the analgesic effect of spinal anesthesia in all groups, the regular use of both diclofenac and paracetamol with the on-demand use of systemic morphine for post-operative analgesia, and the fact of their using lower doses of gabapentin (300 mg and $600 \mathrm{mg}$ ) than the dose we used in our study $(900 \mathrm{mg}$ ). None of the patients included in this study asked for supplemental analgesia, as it could mask the analgesic effect or increase incidence of the study drugs complications.

\section{Results}

Among 75 female patients aged from 20 to 60 years old, with ASA physical status I - II, scheduled for elective gynecological surgeries, 25 cases received $900 \mathrm{mg}$ gabapentin (group B), 25 cases received $300 \mathrm{mg}$ pregabalin (group C) and 25 received placebo capsules (group A) 1 hour preoperative, 6 cases were recorded as failed cases and excluded from the study 3 of which because of pain felt at skin incision indicating block failure, and the other 3 cases due to complicated and prolonged surgery more than 3.5 hours requiring initiation of general anesthesia, and these excluded cases were replaced by equal number of cases.

As regard type of gynecological procedures, we included different types of surgeries shown in Table 1 and Figure 2.

As for demographic data between the three groups, no significance was found as regard the p-value in patients age (0.788), BMI (0.405), ASA classification (0.749), and duration of surgery (0.612) Table 2.

As for the Duration of motor block between the three groups, no significance was found but high significance was found as regard the p-value between patients who used pregabalin or gabapentin preemptively and those who took placeo, while no significance was found between both of them (Table 3, Figure 3).

While, the statistically significant difference between groups $\mathrm{A}$ with $\mathrm{B} \& \mathrm{C}$ according to duration of effective analgesia ( $\mathrm{min}$ ) is shown in Figure 4. 
As for rescue analgesia with mepredine, significance was also found between both drugs and placebo as shown in Table 4 .

High statistical significant difference was found in VAS score between drug groups \& placebo after 6, 12, 18 and 24 hours (Table 5).

While, the statistically significant difference between groups A with B\&C according to VAS from VAS $6 \mathrm{hr}$ to VAS $24 \mathrm{hr}$ is shown in Table 6.

Significant difference between groups A with B\&C according to VAS at time of regaining full muscle power is shown in Figure 5.

As for the complications, both drugs had increased incidence of nausea, vomiting and dizziness postoperatively $\mathrm{p}$-value $(<0.001)$, while no significance was found between all groups as regard hypotension, bradycardia and shivering (Table 7).

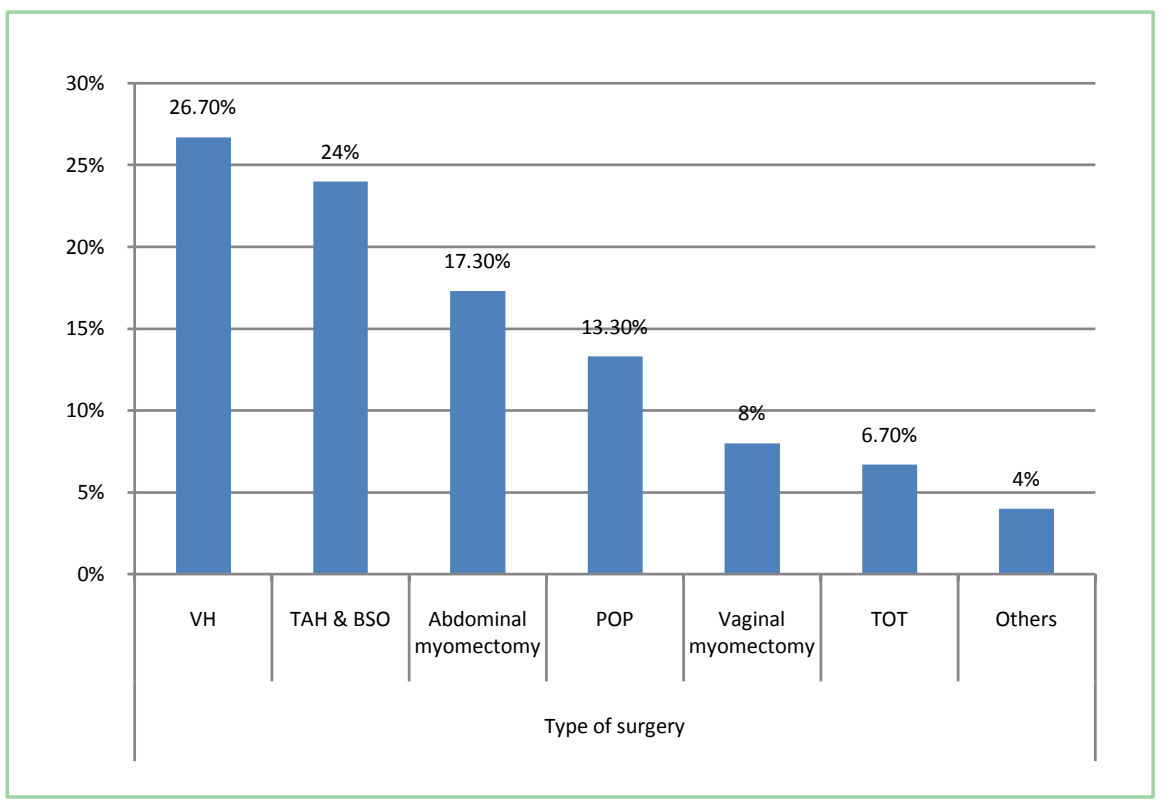

Figure 2. Type of surgery.

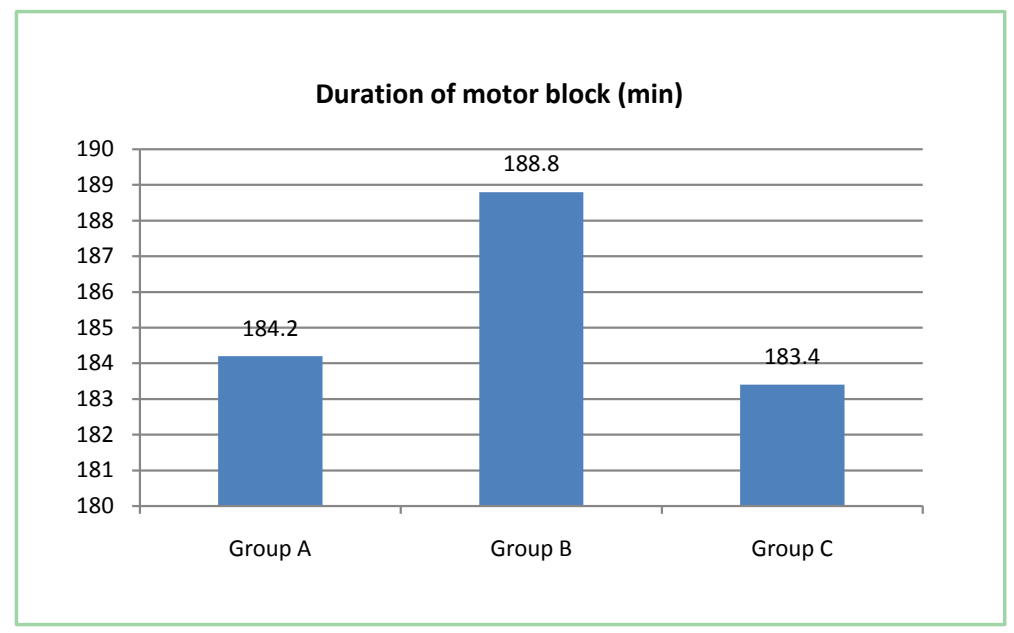

Figure 3. Duration of motor block. 


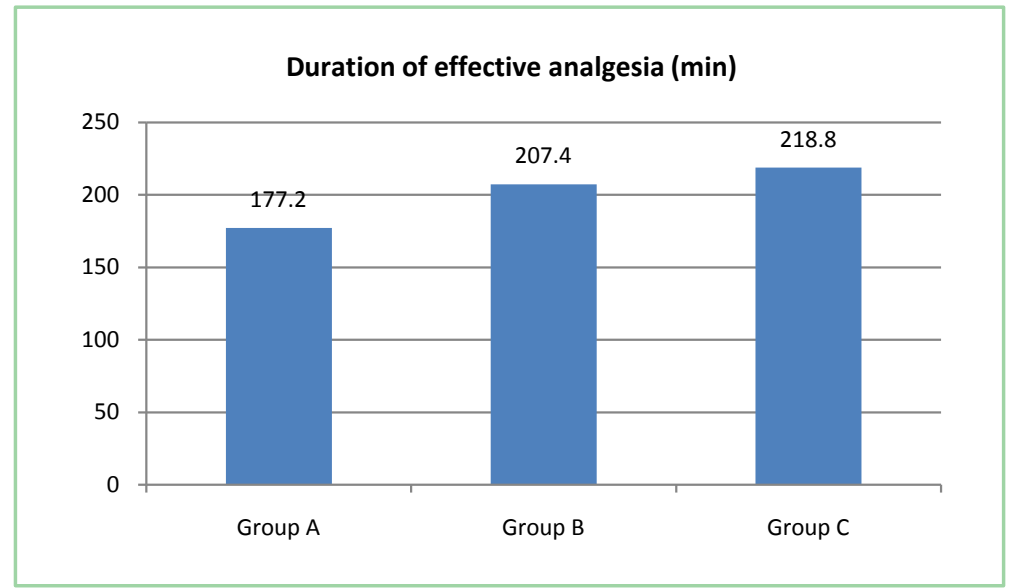

Figure 4. Duration of effective analgesia.

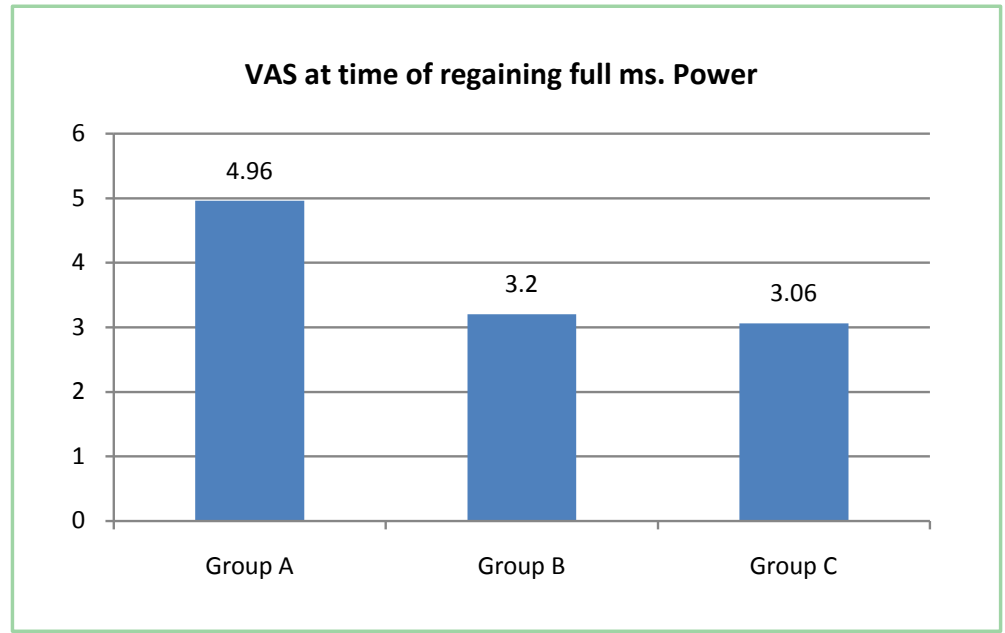

Figure 5. VAS at time of regaining full ms. Power.

Table 1. Percentages of different types of elective gynecological surgeries encountered in this study.

\begin{tabular}{|c|c|c|}
\hline Type of surgery & Number of cases & Percentage \\
\hline Vaginal hysterectomy $(\mathrm{VH})$ & 20 & $26.7 \%$ \\
\hline $\begin{array}{l}\text { Total abdominal hysterectomy and bilateral } \\
\text { salpingo-oophorectomy (TAH \& BSO) }\end{array}$ & 18 & $24 \%$ \\
\hline Abdominal myomectomy & 13 & $17.3 \%$ \\
\hline $\begin{array}{l}\text { Pelvic organ Prolapse (POP) repair surgeries: } \\
\text { - Anterior colporrhaphy. } \\
\text { - Anterior colporrhaphy with graft. } \\
\text { - Paravaginal repair (abdominal/vaginal) }\end{array}$ & 10 & $13.3 \%$ \\
\hline Vaginal myomectomy & 6 & $8 \%$ \\
\hline Trans-obturator vaginal tape (TOT) & 5 & $6.7 \%$ \\
\hline $\begin{array}{l}\text { Others: } \\
\text { - Secondry suturing. } \\
\text { - Ovarian cystectomy. } \\
\text { - Excision of vulval cancer }\end{array}$ & 3 & $4 \%$ \\
\hline
\end{tabular}


Table 2. Comparison between groups according to demographic data.

\begin{tabular}{ccccc}
\hline Demographic Data & $\begin{array}{c}\text { Group A } \\
\mathbf{n}=25\end{array}$ & $\begin{array}{c}\text { Group B } \\
\mathbf{n}=25\end{array}$ & $\begin{array}{c}\text { Group C } \\
\mathbf{n}=25\end{array}$ & p-value \\
\hline Age (years) & $41.68 \pm 9.84$ & $40.68 \pm 9.84$ & $39.76 \pm 9.81$ & 0.788 \\
BMI [wt/(ht) ${ }^{2}$ ) & $28.64 \pm 3.81$ & $29.40 \pm 3.35$ & $28.04 \pm 3.51$ & 0.405 \\
ASA & $17(68.0 \%)$ & $17(68.0 \%)$ & $16(64.0 \%)$ & $0.749 \#$ \\
I & $8(32.0 \%)$ & $8(32.0 \%)$ & $9(36.0 \%)$ & \\
II & $126 \pm 15.3$ & $123 \pm 17.4$ & $124 \pm 16.9$ & 0.612 \\
\hline
\end{tabular}

F-ANOVA test, $\# \mathrm{x}^{2}$ : Chi-square test, $\mathrm{p}$-value $<0.05$ significant.

Table 3. Comparison between groups according to duration of motor block and effective analgesia.

\begin{tabular}{|c|c|c|c|c|c|c|}
\hline & \multirow{2}{*}{$\begin{array}{c}\text { Group A } \\
\mathrm{n}=25\end{array}$} & \multirow{2}{*}{$\begin{array}{c}\text { Group B } \\
\mathrm{n}=25\end{array}$} & \multirow{2}{*}{$\begin{array}{c}\text { Group C } \\
n=25\end{array}$} & \multicolumn{3}{|c|}{ P-value } \\
\hline & & & & A vs. $B$ & A vs. $C$ & B vs. $C$ \\
\hline $\begin{array}{l}\text { Duration of motor } \\
\text { block (min) }\end{array}$ & $184.20 \pm 17.95$ & $188.80 \pm 23.29$ & $183.40 \pm 24.44$ & 0.616 & 0.713 & 0.421 \\
\hline $\begin{array}{c}\text { Duration of effective } \\
\text { analgesia (min) }\end{array}$ & $177.20 \pm 20.37$ & $207.40 \pm 23.36$ & $218.80 \pm 23.64$ & $<0.001^{\star}$ & $<0.001^{\star}$ & 0.227 \\
\hline
\end{tabular}

Using: ANOVA test (Post Hoc). ${ }^{*}$ p-value $<0.05$ significant.

Table 4. Comparison between groups according to number of meperedine doses.

\begin{tabular}{lcccccc}
\hline & $\begin{array}{c}\text { Group A } \\
\mathrm{n}=25\end{array}$ & $\begin{array}{c}\text { Group B } \\
\mathrm{n}=25\end{array}$ & $\begin{array}{c}\text { Group C } \\
\mathrm{n}=25\end{array}$ & & \multicolumn{3}{c}{ P-value } \\
\cline { 5 - 7 } & & & A vs. B & A vs. C & B vs. C \\
\hline $\begin{array}{c}\text { No. of meperedine } \\
\text { doses in 24 hr. }\end{array}$ & $2.40 \pm 0.50$ & $1.11 \pm 0.69$ & $0.98 \pm 0.58$ & $<0.001^{\star}$ & $<0.001^{*}$ & 0.099 \\
\hline
\end{tabular}

Using: ANOVA test (Post HOC). ${ }^{*}$ p-value $<0.05$ significant.

Table 5. Comparison between groups according to VAS.

\begin{tabular}{ccccccc}
\hline VAS & Group A & Group B & Group C & \multicolumn{3}{c}{ P-value } \\
\cline { 6 - 7 } & $\mathbf{n}=\mathbf{2 5}$ & $\mathbf{n}=25$ & $\mathbf{n}=25$ & A vs. B & A vs. C & B vs. C \\
\hline VAS 0 hr & $0.84 \pm 0.85$ & $0.78 \pm 0.58$ & $0.77 \pm 0.50$ & 0.391 & 0.453 & 0.268 \\
VAS 6 hr & $5.24 \pm 1.16$ & $3.36 \pm 0.86$ & $3.18 \pm 1.00$ & $<0.001^{*}$ & $<0.001^{*}$ & 0.186 \\
VAS12 hr & $5.40 \pm 1.55$ & $3.84 \pm 0.99$ & $3.42 \pm 1.42$ & $<0.001^{*}$ & $<0.001^{*}$ & 0.216 \\
VAS18 hr & $4.28 \pm 1.28$ & $2.92 \pm 1.00$ & $2.36 \pm 1.11$ & $<0.001^{*}$ & $<0.001^{*}$ & 0.127 \\
VAS 24 hr & $2.40 \pm 0.96$ & $1.64 \pm 0.64$ & $1.44 \pm 0.71$ & $<0.001^{*}$ & $<0.001^{*}$ & 0.069 \\
\hline
\end{tabular}

Using: ANOVA test (Post HOC). ${ }^{\star}$ p-value $<0.05$ significant.

Table 6. Comparison between groups according to VAS at time of regaining full muscle power.

\begin{tabular}{ccccccc}
\hline & Group A & Group B & Group C & \multicolumn{2}{c}{ P-value } \\
\cline { 5 - 7 } & $\mathbf{n}=25$ & $\mathbf{n = 2 5}$ & $\mathbf{n = 2 5}$ & A vs. B & A vs. C & B vs. C \\
\hline $\begin{array}{c}\text { VAS at time of } \\
\text { regaining full ms. Power }\end{array}$ & $4.96 \pm 0.84$ & $3.20 \pm 0.65$ & $3.06 \pm 0.85$ & $<0.001^{*}$ & $<0.001^{*}$ & 0.296 \\
\hline
\end{tabular}

Using: ANOVA test (Post HOC). ${ }^{\star}$ p-value $<0.05$ significant. 
Table 7. Comparison between groups according to complications.

\begin{tabular}{cccccccc}
\hline \multirow{2}{*}{ Complications } & \multirow{2}{*}{ Group A } & Group B & Group C & \multicolumn{3}{c}{ P-value } \\
\cline { 6 - 8 } & $\mathbf{n}=\mathbf{2 5}$ & $\mathbf{n}=\mathbf{2 5}$ & $\mathbf{n}=\mathbf{2 5}$ & A vs. B & A vs. C & B vs. C \\
\hline Hypotension & $9(36.0 \%)$ & $9(36.0 \%)$ & $9(36.0 \%)$ & 1.000 & 1.000 & 1.000 \\
Bradycardia & $3(12.0 \%)$ & $3(12.0 \%)$ & $5(20.0 \%)$ & 0.620 & 0.718 & 0.424 \\
Shivering & $9(36.0 \%)$ & $12(48.0 \%)$ & $12(48.0 \%)$ & 0.124 & 0.144 & 0.085 \\
Nausea & $19(76.0 \%)$ & $10(40.0 \%)$ & $8(32.0 \%)$ & $0.022^{*}$ & $0.017^{*}$ & 0.215 \\
Vomiting & $17(68.0 \%)$ & $6(24.0 \%)$ & $4(16.0 \%)$ & $<0.001^{*}$ & $<0.001^{*}$ & 0.272 \\
Dizziness & $1(4.0 \%)$ & $17(68.0 \%)$ & $18(72.0 \%)$ & $<0.001^{*}$ & $<0.001^{*}$ & 0.398 \\
\hline
\end{tabular}

Using: $\mathrm{x}^{2}$ : Chi-square test. ${ }^{*} \mathrm{p}$-value $<0.05$ significant.

\section{Conclusion}

Preoperative use of pregabalin or gabapentin provides comparable but significant prolonged postoperative analgesia, less nausea and vomiting compared to placebo after gynecological surgeries. However, it was associated with increased incidence of postoperative dizziness.

\section{Conflicts of Interest}

The authors declare no conflicts of interest regarding the publication of this paper.

\section{References}

[1] Fassoulaki, A., Melemeni, A., Tsaroucha, A. and Paraskeva, A. (2012) Perioperative Pregabalin for Acute and Chronic Pain after Abdominal Hysterectomy or Myomectomy: A Randomized Controlled Trial. European Journal of Anaesthesiology, 29, 531-536. https://doi.org/10.1097/EJA.0b013e32835800e0

[2] Levaux, C., Bonhomme, V., Dewandre, P.Y., Brichant, J.F. and Hans, P. (2003) Effect of Intra-Operative Magnesium Sulphate on Pain Relief and Patient Comfort after Major Lumbar Orthopaedic Surgery. Anaesthesia, 58, 131-135. https://doi.org/10.1046/j.1365-2044.2003.02999.x

[3] Zhang, J., Ho, K.Y. and Wang, Y (2011) Efficacy of Pregabalin in Acute Postoperative Pain: A Meta-Analysis. British Journal of Anaesthesia, 106, 454-462. https://doi.org/10.1093/bja/aer027

[4] Dahl, J.B. and Møiniche, S. (2004) Pre-Emptive Analgesia. British Medical Bulletin, 71, 13-27. https://doi.org/10.1093/bmb/ldh030

[5] Kersten, P., Küçükdeveci, A.A. and Tennant, A. (2012) The Use of the Visual Analogue Scale (VAS) in Rehabilitation Outcomes. Journal of Rehabilitation Medicine, 44, 609-610. https://doi.org/10.2340/16501977-0999

[6] Turan, A., Karamanlioglu, B., Memis, D., et al. (2004) Analgesic Effects of Gabapentin after Spinal Surgery. Anesthesiology, 100, 935-938. https://doi.org/10.1097/00000542-200404000-00025

[7] Tiippana, E.M., Hamunen, K., Kontinen, V.K. and Kalso, E. (2007) Do Surgical Patients Benefit from Perioperative Gabapentin/Pregabalin? A Systematic Review of Efficacy and Safety. Anesthesia \& Analgesia, 104, 1545-1556. https://doi.org/10.1213/01.ane.0000261517.27532.80 
[8] Yu, L., Ran, B., Li, M. and Shi, Z. (2013) Gabapentin and Pregabalin in the Management of Postoperative Pain after Lumbar Spinal Surgery: A Systematic Review and Meta-Analysis. Spine, 38, 1947-1952. https://doi.org/10.1097/BRS.0b013e3182a69b90

[9] Kehlet, H. and Dahl, J.B. (1993) The Value of "Multimodal" or "Balanced Analgesia" in Postoperative Pain Treatment. Anesthesia \& Analgesia, 77, 1048-1056. https://doi.org/10.1213/00000539-199311000-00030

[10] Pogatzki-Zahn, E.M., Zahn, P.K. and Brennan, T.J. (2007) Postoperative Pain: Clinical Implications of Basic Research. Best Practice \& Research Clinical Anaesthesiology, 21, 3-13. https://doi.org/10.1016/j.bpa.2006.11.003

[11] Ghai, A., Gupta, M., Hooda, S., Singla, D. and Wadhera, R. (2011) Randomization Controlled Trial to Compare Pregabalin with Gabapentin for Postoperative Pain in Abdominal Hysterectomy. Saudi Journal of Anaesthesia, 5, 252-257. https://doi.org/10.4103/1658-354X.84097

[12] Bafna, U., Rajarajeshwaran, K., Khandelwal, M. and Verma, A.P. (2014) A Comparison of Effect of Preemptive Use of Oral Gabapentin and Pregabalin for Acute Post-Operative Pain after Surgery under Spinal Anesthesia. Journal of Anaesthesiology Clinical Pharmacology, 30, 373-377. https://doi.org/10.4103/0970-9185.137270

[13] Kohli, M., Murali, T., Gupta, R., et al. (2011) Optimization of Subarachanoid Block by Oral Pregabalin for Hysterectomy. Journal of Anaesthesiology Clinical Pharmacology, 27, 101-105.

[14] Short, J., Downey, K., Bernstein, P., Shah, V. and Carvalho, J.C. (2012) A Single Preoperative Dose of Gabapentin Does Not Improve Postcesarean Delivery Pain Management: A Randomized, Double-Blind, Placebo-Controlled Dose-Finding Trial. Anesthesia \& Analgesia, 115, 1336-1342. https://doi.org/10.1213/ANE.0b013e31826ac3b9 